\title{
Exploring the Beauty of Mathematics with Mathematica
}

\author{
Tom Wickham-Jones \\ Wolfram Research \\ United Kingdom \\ www.wolfram.com
}

\section{KEYNOTE ABSTRACT}

This talk will use the computational tool Mathematica (www.wolfram.com) to investigate the aesthetic enjoyment to be gained from mathematics. It will consider the intrinsic beauty found in mathematical proofs and visualisation of mathematical forms, showing how advances in technologies, such as mechanical computation, two and three-dimensional printing, as well as the programmable computer, help to widen access and deepen insight. Finally, it will examine the boundaries and synergies between mathematics and creative expressions such as art, music and architecture, taking examples drawn from antiquity through to the modern era.

\section{BIBLIOGRAPHY}

Bakshee, I. (1999) Graphica 2. The Pattern of Beauty: The Art of Igor Bakshee. Wolfram Media. ISBN 978-1579550103.

Trott, M. (2002) Graphica 1. The Imaginary Made Real: The Art of Michael Trott. Wolfram Media. ISBN 978-1579550097.

Wickham-Jones, T. (1994) Mathematica Graphics: Techniques \& Applications. Springer. ISBN 9780387940472. 